\section{CONGENITAL IMPERFOIATIE ANUS, WITH OCCLUSION OF ENTIRE COLON}

\section{H. HAMILTON, M.D. \\ SUGAR GROVE, 0.}

The patient was a male infant, born Oct. 13, 1911. The parents are licalthy, but father is 71 years old, and mother, 36 . The patient was the second child born to this couple. The other child, uged 5 , is healthy but is backward and otherwise defective mentally. In the case under consideration labor was normul, with the exception of some dystocia due to enormonsly distended abdomen due to gas. It was found that no opening existed between the aual aperture and the rectum. This was punctured and the opening dilated, partially relieving the dis. tention. The child lived four days; it took very little nourishment, but there was no vomiting. The distention remained throughont. Autopsy revealed that while the small intestines were normal, the colon was undeveloped, being about $1 \mathrm{~cm}$. in diameter, and was constricted at intervals of about $8 \mathrm{~cm}$. throughout its entire course.

\section{Therapeutics}

\section{PRURITUS ANI}

Whether one regards pruritus ani as a distinct disease, or only as a symptom of some, underlying condition, it must be realized that the disease or condition, whichever one chooses to call it, is a very frequent one. It is often, also, a very obstinate and troublesome one to treat successfully. 'There is therefore a certain propriety in frequent discussion of the subject, even at the risk of considerable repetition. In order to be certain that good therapeutic measures are not forgotten, they must be frequently brought to mind. It is not proposed at the present time to treat exhaustively this subject, but to recall some of the more important and more useful aids to successful treatment, and to mention also some which have not been recently referred to.

The physician should not advise any course of treatment or prescribe any medicine until he has made a careful examination of the patient in order to determine, if possible, what the underlying cause of the affection is, or if he cannot find that cause, at least to exclude the common causes which, when they are present, may be easily detected. These causes are the Ascaris vermicularis, a fistula in ano, and fissures. Hemorrhoids may be present, but are less frequently accompanied hy pruritus. Small ulcers in the mucous lining of the rectum, and especially between the mucocutaneous border and the internal sphineter, are frequently overlooked, though they are often associated with pruritus. Some writers assert that these are present in the majority of cases of pruritus ani.

If none of these conditions is present, it may be possible to learn of a condition of excessive moisture on the skin in the anal region, due to abnormal secretion of the sudoriparous or sebaceous glands, which is encouraged and increased by the friction of the parts and by the local heat induced by exercise. Sometimes a condition of irritable spasmodic contraction of the sphincter may be discovered.

If none of the alove conditions is found, inquiry should be made as to the presence of chronic constipation, of intestinal fermentation, especially of putrefaction of proteins, and of congestion of the vessels of the rectum attendant on congestion and sluggish circulation in the liver.
Having made inquiry with refercence to all of these conditions which may be present in different cases of pruritus ani, one is better prepared to adopt the line of treatment which may promise some hope of success.

The diet should be regulated. Alcoholic beverages, and often tea, coffee and even cocoa should be avoided. Sugar should be greatly reduced. Eating between meals, and eating to excess should be forbidden.

Regard slould be had for the clothing. Overhenting. of the body is undesirable, and it is better, except in the very coldest of winter weather, to wear linen rather than wool next to the skin.

All the excretory functions should be maintained in a state of activity. If the urine is of high specific gravity and strongly acid, alkalies and plenty of water should be prescribed. If the bowels do not move freely every day, laxatives should be given. If the patient is plethoric and stout, a saline laxative may be ordered before breakfnst; if the patient is thin and anemic and has a poor appetite, a small dose of rhamnus purshiana should be prescribed, to be taken three times a day, before eating.

If the Ascarides vermiculares are present, an encma of a strong solution of sodium chlorid, or an infusion of quassia should be used once a day for four or five dars.

If hemorrhoids or a fistula are present they should be treated by operation. If a fissure or an ulcer has been found, it should receive proper treatment. 'This means stretching the sphincter ani and applying nitrate of silver or the actual cautery to the sore.

In most cases there is some enlargement of the hemorrhoidal vessels, even if actual hemorrhoids are not present. For this condition, some time ago (New York Med. Jour., July 29, 1905) Dr. Lewis H. Adler, Jr., of Pliladelphia, recommended the injection of the following:

R

Fluidextracti ergotæ ......... 8

Fluidextracti liydrastis ......... 8

Tinctura benzoini compositæ $\ldots \ldots \ldots, 8$

Fludextracti hamamelidis .......

or

M. et Sig.: Inject 1 or 2 teaspoonfuls, daily, as directed.

Shake.

It has been frequently recommended to paint a strong solution of nitrate of silver on the skin around the anus, such an application to be repéated several times at intervals of four or five days.

If the patient is not sufficiently annoyed by the trouble to lead him to follow up a regular course of treatment. other palliative measures will sometimes afford considerable relief.

Two drugs are exceedingly useful in relieving itching. These'are phenol (carbolic acid) and menthol. The phenol may be used in aqueous solution, or in an ointment; which is preferable depends somewhint on the condition of the skin. If the skin is dry and rough, an ointment is often useful. If, on the other hand, the skin is smooth with a tendency to be moist, an aqueous mixture is often preferable. At the same time, it must be remembered that water usually acts as an irritant to the skin. To prevent this a small amount of glycerin may be used, as in the following combination:

R $\quad \mathrm{Gm}$. or c.c.

Plienolis liquefacti $\ldots . . . \ldots \ldots \ldots . .5$ Glycerini $\ldots \ldots \ldots \ldots \ldots \ldots \ldots, \mathbf{5}$

Aquæ q. s. ................ ad 100 ad fi. fiv $^{2}$

M. et Sig.: Apply externally. 